\title{
Transcatheter therapies have not forgotten the tricuspid valve
}

\author{
Toby Rogers, $\mathrm{MD}, \mathrm{PhD},{ }^{\mathrm{a}}$ and Vinod $\mathrm{H}$. Thourani, $\mathrm{MD}^{\mathrm{b}}$
}

\footnotetext{
From the ${ }^{\mathrm{a} S e c t i o n}$ of Interventional Cardiology, and ${ }^{\mathrm{b}}$ Department of Cardiac Surgery, MedStar Heart and Vascular Institute, Georgetown University School of Medicine, Washington, DC.

Disclosures: T.R.: Consultant: Medtronic. Intellectual property: co-inventor on patents, assigned to the National Institutes of Health, for transcatheter devices to treat TR. V.H.T.: Advisor/Research: Edwards Lifesciences, Abbott Vascular, Claret Medical, Boston Scientific, Gore Vascular, and JenaValve.

Received for publication April 21, 2018; revisions received April 21, 2018; accepted for publication April 23, 2018; available ahead of print July 17, 2018.

Address for reprints: Vinod H. Thourani, MD, MedStar Heart and Vascular Institute, MedStar Washington Hospital Center, 110 Irving St NW, Room 6D15G, Washington, DC 20010 (E-mail: vinod.h.thourani@ medstar.net)

J Thorac Cardiovasc Surg 2018;156:1067-8

$0022-5223 / \$ 36.00$

Copyright $(2018$ by The American Association for Thoracic Surgery

https://doi.org/10.1016/j.jtcvs.2018.04.113
}

The tricuspid valve is an attractive target for percutaneous transcatheter therapies because isolated tricuspid valve surgery is associated with high mortality and is seldom undertaken. ${ }^{1,2}$ Tricuspid regurgitation (TR) is a predictor of mortality, independent of age, biventricular function, or pulmonary artery pressure. ${ }^{3}$ In patients with mitral regurgitation or undergoing left-sided valve surgery, presence of TR is associated with acute heart failure episodes and worse outcomes. ${ }^{4,5}$ Furthermore, persistent TR after left-sided valve surgery is also associated with worse outcomes. ${ }^{6}$ Tricuspid annuloplasty is a simple, yet effective adjunct to open aortic or mitral valve repair or replacement. But as more and more patients undergo transcatheter procedures for aortic or mitral valve disease, the need for safe and effective transcatheter therapies for TR becomes increasingly realistic.

Most clinical TR is secondary to dilation of the right ventricle caused by volume or pressure overload leading to dilation of the tricuspid annulus. ${ }^{7}$ Less commonly, dilation results from primary right ventricular pathology, such as right ventricular infarction or cardiomyopathy. The severity of TR correlates with the dimensions of the tricuspid annulus, which dilates primarily in the septallateral dimension. ${ }^{8}$ Furthermore, because TR severity is a dynamic process with variability based on preload and afterload conditions, guidelines for therapy based on echocardiography have not been well defined.

The field of transcatheter tricuspid valve repair is fertile, with a number of techniques and devices now undergoing early clinical testing. Many of these devices emulate established surgical tricuspid repair techniques and can be divided into 3 broad approaches: (1) tricuspid annuloplasty devices; (2) leaflet edge-to-edge plication; and (3) devices to plug the regurgitant orifice. ${ }^{9}$ The diseased tricuspid valve presents several key challenges for each of these different leaflet.

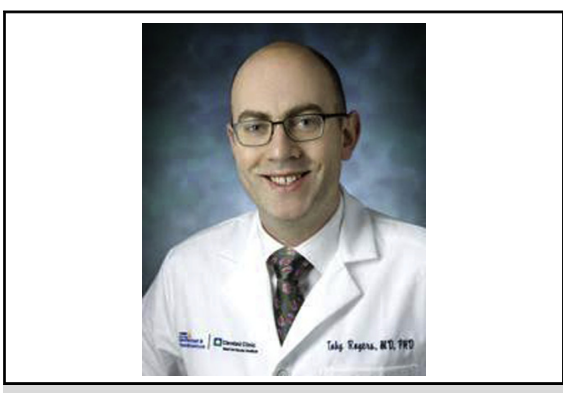

Toby Rogers, MD, PhD

Central Message

Transcatheter treatment of TR is an evolving field for those patients considered high risk for surgical therapy.

See Article page 1064 .

approaches. First, by the time symptoms manifest, the dilated tricuspid annulus is often very large, and therefore effective annuloplasty is dependent on substantial reduction in annular circumference. Second, the right coronary artery and atrioventricular node lie in close proximity to the tricuspid annulus and are vulnerable to injury during transcatheter interventions. Third, the valve is trileaflet with complex subvalvular apparatus rendering edge-to-edge leaflet plication more difficult compared with the relatively simpler bileaflet mitral valve. Fourth, although plugging the central regurgitant orifices caused by leaflet malcoaptation may reduce $\mathrm{TR}$ in the short term, inexorable further dilation of the annulus will lead to recurrent TR in the longer term. Last, in many instances, the TR is secondary to pacemaker leads, which are commonly not amenable to transcatheter options and lead to a diminutive septal tricuspid valve

Percutaneous tricuspid valve replacement may circumvent many of these challenges and may be preferable to repair. Only 1 dedicated device has reached clinical testing to date: the Gate Tricuspid Valve Stent (NaviGate Cardiac Structures, Lake Forest, Calif). In this issue of the Journal, Colli and colleagues ${ }^{10}$ report the use of this device in a symptomatic 66-year-old man who presented 27 years after heart transplantation with medically refractory severe TR with ascites and deranged liver synthetic function. Because the diseased tricuspid annulus was so large $(43 \mathrm{~mm})$, the prosthesis was also large $(52 \mathrm{~mm})$. Percutaneous delivery is difficult because the introducer sheath is $42 \mathrm{~F}$ to 
accommodate the $36 \mathrm{~F}$ Gate valve delivery catheter, leading to a surgical cut-down of the internal jugular vein. Arterial access was obtained for right coronary artery selective angiography during valve deployment to aid in localizing the annular plan on fluoroscopy and to ensure patency. The implant was successful with only mild residual paravalvular $\mathrm{TR}$, and at 6-month follow-up the patient was asymptomatic, which is very encouraging. Heart block developed in the patient 2 months after the implant, which was likely related to mechanical compression on the atrioventricular node from the Gate bioprosthesis. A leadless pacemaker was subsequently implanted, but this is an imperfect solution for a relatively young patient in whom atrioventricular synchrony is desirable.

Mirroring the eternal debate of mitral valve repair versus replacement, it remains to be seen whether tricuspid valve replacement is superior to repair. It is important to recognize that this technology remains in its infancy, and many questions remain unanswered. Specifically, what is the expected durability of the Gate tricuspid valve stent in the slow-flow right-sided circulation? What will remain of the anticoagulation in these patients? Should a pacemaker be implanted in every patient before valve replacement to anticipate late atrioventricular block? Can the device and delivery system be further miniaturized to allow fully percutaneous delivery? Finally, should transcatheter tricuspid valve replacement be reserved for symptom palliation in patients who do not qualify for transcatheter repair or be the primary treatment strategy for all patients with symptomatic severe TR? Despite the many unanswered questions regarding these technologies, we are excited about the future of novel technologies in the management of the forgotten valve!

\section{References}

1. Mangoni AA, DiSalvo TG, Vlahakes GJ, Polanczyk CA, Fifer MA. Outcome following isolated tricuspid valve replacement. Eur J Cardiothorac Surg. 2001;19:68-73.

2. Kwon DA, Park JS, Chang HJ, Kim YJ, Sohn DW, Kim KB, et al. Prediction of outcome in patients undergoing surgery for severe tricuspid regurgitation following mitral valve surgery and role of tricuspid annular systolic velocity. Am J Cardiol. 2006;98:659-61.

3. Nath J, Foster E, Heidenreich PA. Impact of tricuspid regurgitation on long-term survival. J Am Coll Cardiol. 2004;43:405-9.

4. Agricola E, Stella S, Gullace M, Ingallina G, D'Amato R, Slavich M, et al. Impact of functional tricuspid regurgitation on heart failure and death in patients with functional mitral regurgitation and left ventricular dysfunction. Eur J Heart Fail. 2012;14:902-8.

5. Turina J, Stark T, Seifert B, Turina M. Predictors of the long-term outcome after combined aortic and mitral valve surgery. Circulation. 1999;100:II48-53.

6. Ruel M, Rubens FD, Masters RG, Pipe AL, Bedard P, Mesana TG. Late incidence and predictors of persistent or recurrent heart failure in patients with mitral prosthetic valves. J Thorac Cardiovasc Surg. 2004;128:278-83.

7. Ton-Nu TT, Levine RA, Handschumacher MD, Dorer DJ, Yosefy C, Fan D, et al. Geometric determinants of functional tricuspid regurgitation: insights from 3dimensional echocardiography. Circulation. 2006;114:143-9.

8. Sugimoto T, Okada M, Ozaki N, Hatakeyama T, Kawahira T. Long-term evaluation of treatment for functional tricuspid regurgitation with regurgitant volume: characteristic differences based on primary cardiac lesion. J Thorac Cardiovasc Surg. 1999; 117:463-71.

9. Latib A, Mangieri A. Transcatheter tricuspid valve repair: new valve, new opportunities, new challenges. J Am Coll Cardiol. 2017;69:1807-10.

10. Colli A, Gerosa G, Bartus K, Tarantini T. Transcatheter tricuspid valve replacement with a self-expanding bioprosthesis. J Thorac Cardiovasc Surg. 2018;156: 1064-6. 